\title{
Mathematics Teachers Educator Specialized Knowledge model
}

\section{Modelo de Conhecimento Especializado para Formadores de Professores de Matemática}

\author{
Federica Ferretti ${ }^{1}$ \\ Francesca Martignone ${ }^{2}$ \\ Luis J. Rodríguez-Muñiz ${ }^{3}$
}

\begin{abstract}
Our research focuses on Mathematics Teacher Educator specialized knowledge. By means theoretical tools driven from Mathematics Teacher Specialized Knowledge model (MTSK model) we focus on teacher educators' specialized knowledge and carry out a qualitative study in order to identify specific dimensions and domains of mathematics teacher educators' specialized knowledge. We explore an extension of the MTSK model that can characterize the teacher educator's specialized knowledge (Mathematics Teacher Educator Specialized Knowledge model) - MTESK model. Specifically, our focus will be on the Pedagogical Content Knowledge of the MTESK model.
\end{abstract}

Keywords: Mathematics teacher educator; Mathematics teacher specialised knowledge; MTESK model; MTSK model.

\section{Resumo}

Nossa pesquisa se concentra no conhecimento especializado dos Professores de Matemática. Por meio de ferramentas teóricas impulsionadas pelo modelo de Conhecimento Especializado de Professores de Matemática (modelo MTSK) nos concentramos no conhecimento especializado dos professores educadores e realizamos um estudo qualitativo a fim de identificar dimensões e domínios específicos do conhecimento especializado dos professores educadores de Matemática. Exploramos uma extensão do modelo MTSK que pode caracterizar o conhecimento especializado do professor educador (modelo de Conhecimento Especializado de Professores de Matemática) - modelo MTESK. Especificamente, nosso foco será o Conhecimento de Conteúdo Pedagógico do modelo MTESK.

Palavras-chave: Educador de professores de matemática; Conhecimento especializado de professores de matemática; modelo MTESK; Modelo MTSK.

Sent on: 06/11/2020 - Accepted on: 05/02/2021 - Published on: 08/06/2021

$1 \mathrm{PhD}$ in Mathematics by the University of Bologna. Researcher at University of Ferrara, Italy. Email: federica.ferretti5@gmail.com. ORCID: https://orcid.org/0000-0002-4956-4136

${ }^{2} \mathrm{PhD}$ in Mathematics by the University of Genoa. Associate Professor at University of Eastern Piedmont, Italy. Email: francesca.martignone@ uniupo.it. ORCID: https://orcid.org/0000-0002-6960-9135

${ }^{3} \mathrm{PhD}$ in Mathematics by the University of Oviedo. Associate Professor at University of Oviedo, Spain. Email: luisj@uniovi.es. ORCID: https://orcid.org/0000-0001-8702-8361 


\section{Introduction}

The growing interest in the professional development of mathematics teacher education is internationally broader and the importance of research in this field is increasingly shared (e.g. Loughran, 2014; Beswick \& Goos, 2018; Llinares \& Krainer, 2006; Ribeiro et al., 2019; Prediger, Roesken-Winter \& Leuders, 2019). One of the germinal works with regard to Mathematics Teacher Educators (MTE) is done by Tzur, who in 2001 deepened themes that should have contributed to thinking and conducting research in the field of development of the educator of mathematics teachers. In details, Tzur highlighted four interconnected dimensions (and related involved profiles) of reflection that must be taken into account in research studies concerning MTE: learning mathematics - student, learning to teach mathematics - teacher, learning to teach mathematics teachers - teacher educator, and learning to teach mathematics teacher educators - mentor (Tzur, 2001).

These ideas have been further developed, hence, in Volume 4 of the International Handbook of Mathematics Teacher Education (2008), Jaworski dedicated the introduction precisely to the knowledge of MTEs. In details, within the diagram of knowledge in teacher education (2008, p. 2), Jaworski underlined the strictly connection between Educators' knowledge of theory, research and system and teachers' knowledge of students and school.

The knowledge of MTEs and the teachers are closely connected and knowledge for teaching mathematics plays a pivotal role. It is precisely from these considerations that our research arose. We conducted a qualitative research aimed to investigate MTEs' beliefs about their specialized knowledge. Starting from the literature evidences that highlight the pivotal and strictly link between the knowledge of teacher educators and teachers, our model is inspired by one of the models currently most shared internationally for the mathematics teachers specialised knowledge, the MTSK (Carrillo-Yáñez et al., 2018). We propose to categorize and frame MTE's beliefs in a germinal model, that we denote Mathematics Teacher Educator Specialised Knowledge - MTESK Model (Martignone, Ferretti \& Rodríguez-Muñiz, submitted). In the current paper we analyse MTEs' beliefs, by particularly specifying some categories of the MTESK Model inherent the MTEs' Pedagogical Content Knowledge.

\section{The MTESK model}

The common feature of many proposed constructs, models and definitions of mathematics teacher educators' knowledge is to start by extending the teachers knowledge needed for teaching (Even, Krainer \& Huang, 2020). In this paper we present a development of the Mathematics Teacher Educator Specialised Knowledge (MTSK model - CarrilloYáñez et- al., 2018).

The MTSK (Figure 1) is a theoretical model on professional knowledge that is specific to teachers of Mathematics, whose constitution considers the advances of previous models (Ball, Thames \& Phelps, 2008; Shulman, 1986) and seeks to overcome their 
DOI: $10.20396 /$ zet.v29i00.8661966

limitations (Flores, Escudero \& Carrillo, 2013; Montes, Aguilar, Carrillo \& Muñoz-Catalán, 2013). This model has two domains - Mathematical Knowledge (MK) and Pedagogical Content Knowledge (PCK) - and each of them is divided into three subdomains.

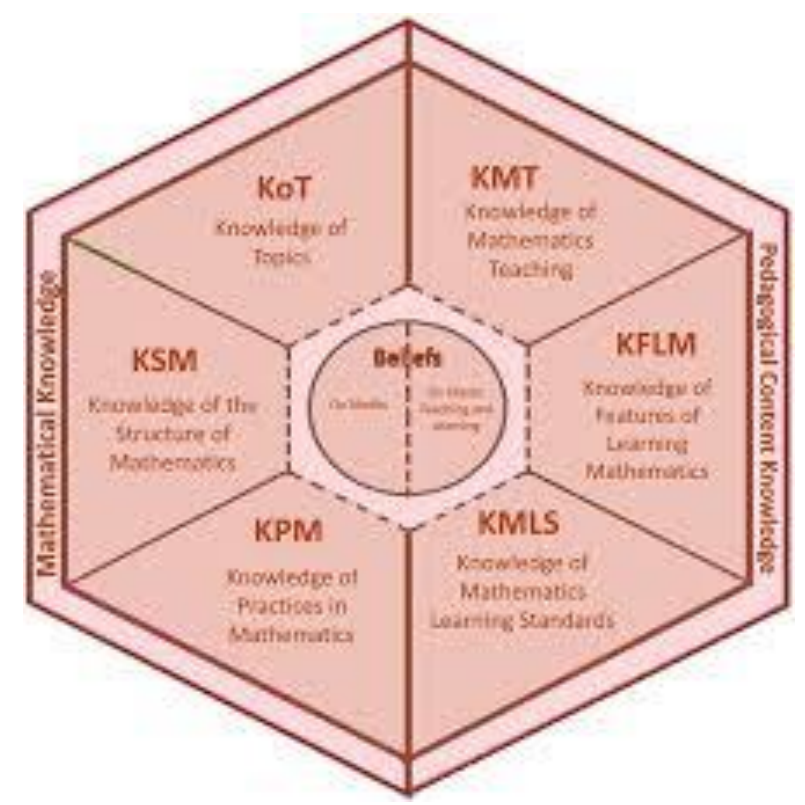

Figure 1 - Mathematics Teacher Specialized Knowledge - MTSK Model Source: Carrillo-Yáñez et al. (2018, p. 241)

Teachers' beliefs about mathematics, its teaching and learning are incorporated into and permeate all the subdomains, as they give meaning to their actions (Carrillo-Yáñez et al., 2018). The MK is divided in three subdomains: Knowledge of Topics (KoT) that includes mathematical content to be taught and its different aspects; Knowledge of the Mathematical Structure (KSM) that deals with the connections between topics that allow the recognition of certain mathematical structures; Knowledge of Mathematical Practice (KPM) that includes ways to proceed in Mathematics, including syntactic knowledge, aspects of mathematical communication, reasoning and proof, ways to select representations, to argue, to generalize, to explore and, yet, how KSM relationships are established. Within the PCK there are the following subdomains: Knowledge of Mathematics Teaching (KMT) including different strategies that allow the teacher to promote the development of mathematical abilities procedural or conceptual; Knowledge of the Learning Features of Mathematics (KFLM) consisting in the characteristics of the students' understanding process about the different contents, possible difficulties or obstacles; Knowledge of Mathematics Learning Standards (KMLS) that is the knowledge about what the student should/can achieve in a course determined school and, in addition to what is prescribed in the institutional curriculum, which comes from research and opinions from expert teachers about learning achievements.

Taking in account the integrated nature of the teacher's knowledge, the MTSK is not intended to induce the idea of an isolated presence of knowledge elements. MTSK aims to help better delineate as a whole specialized knowledge needed to teach mathematics 
(Carrillo-Yáñez et al., 2018). In our study we propose a development of the MTSK model focused on MTE's specialised Knowledge: the MTSEK model (Mathematics Teacher Educators' Specialized Knowledge model).

\section{MTESK Model construction}

In our qualitative research, we collected and analysed some interviews carried out in Italy and Spain. The sample consisted of 13 MTEs from Italy and from Spain who voluntarily participated in the study. They have different backgrounds and teaching experiences but this fact does not constitute a severe limitation in the scope: as a matter of fact, it was not our purpose to carry out a comparative study. On the other hand, it is important to stress that we carried out a qualitative analysis because we aimed at rising hypothesis to identify some specific domains of teacher educators' specialised knowledge, declared by mathematics teacher educators in their answers. We asked MTEs two questions: "What knowledge and skills do you think someone needs to become a Mathematics Teacher Educator? What characteristics do you think a 'good' MTE should have?'. Depending on the availability of the interviewees, we used a face-to-face or online oral interview (recorded and transcribed) or a written form, using the mother tongue of the interviewees (Italian or Spanish). No matter how it was conducted, we did not interact during the interviews, giving total freedom of expression without limiting time or length for the answers. The data gathered by the questionnaire were analysed through an inductive content analysis (Patton, 2002). At first a top-down analysis and then a bottom-up analysis were performed, by using the theoretical lenses provided by the MTESK. We carried out a parallel analysis and then exchanged the extracted data to cross-check consistency of classifications. We divided MTEs' answers according to recurrent features and items emerging from the interviews. We propose a possible adaptation of the MTSK model for MTE knowledge by highlighting the metafeatures of the MTE knowledge and by identifying domains to be added or refined. As the MTSK regards teachers, the MTESK model pursues to bring a perspective and tool for analysing the knowledge that the MTE shows, declares or possesses. In the following figure the first draft for the MTESK Model and its evolution from the MTSK model are shown (Figure 2). By keeping the original hexagonal shape of the MTSK, the MTESK Model has been divided into two main domains: Mathematical Knowledge - MK and Pedagogical Content Knowledge -PCK. The fact that one model is the projection of the other is to emphasize the meta-feature of MTE knowledge. Though the structures of the two models are similar, each subdomain of the MTESK has its own specificity which distinguishes it from the respective subdomain in the MTSK model.

In this paper we will focus on the refinement of the MTSK model for MTEs regarding PCK. The PCK domain overcome a new specific subdomain, the so-called Knowledge of Research in Mathematics Education (KoMER). Unlike the others, this subdomain is not distinct, but is closely connected and transversal to the subdomains KMT and KFLM. For sure, the knowledge of the research studies in mathematics education that the MTE should possess covers both the conceptual, theoretical and practical aspects of mathematics teaching 
DOI: $10.20396 /$ zet.v29i00.8661966

and the characteristics of the mathematics learning process. We also have to point out some considerations about this subdomain. One can wonder if knowing the research in mathematics education should not be also part of the PCK of a mathematics teacher, something that belong both to KMT and KFLM, and it is actually like this: a mathematics teacher should know the main basis and principles of mathematics education research. However, in our case study we have found distinctive nuances for the case of MTEs which go further than something that should be learnt during the initial training of a mathematics teacher. The KoMER in this case goes further than that basic knowledge as it seems to be much more linked to keep updated about recent research in mathematics education. From the analysis of the answers given by MTEs on the characteristics of a "good MTE", this component seems to emerge strongly. We need to investigate this in more detail in order to determine its nature and features and its differential aspects to the case of a mathematics teacher.

Another important difference between the MTESK and the MTSK lies in the further subdivision involving the subdomains KMT and KFLM. For both the teaching and learning aspects of mathematics it is necessary to distinguish whether it refers to the teaching/learning processes of students or teachers. Obviously, when participating in the teaching/learning processes for mathematics teachers, the mathematics teacher educator has a double facet: as educator and as a learner, and also the role of broker between different communities (Krainer, Chapman \& Zaslavsky, 2020; Rasmussen, Zandieh \& Wawro, 2009; Aldon et al., 2013). In a similar way, the teacher who is being trained (both pre-service and in-service) combines two facets: as a student but also as a teacher since he/she is being trained about his/her teaching experience. This unfolded facet explains the reason why we have subdivided each one of the originals subdomains KMT and KFLM into their respective areas concerning students and teachers. 


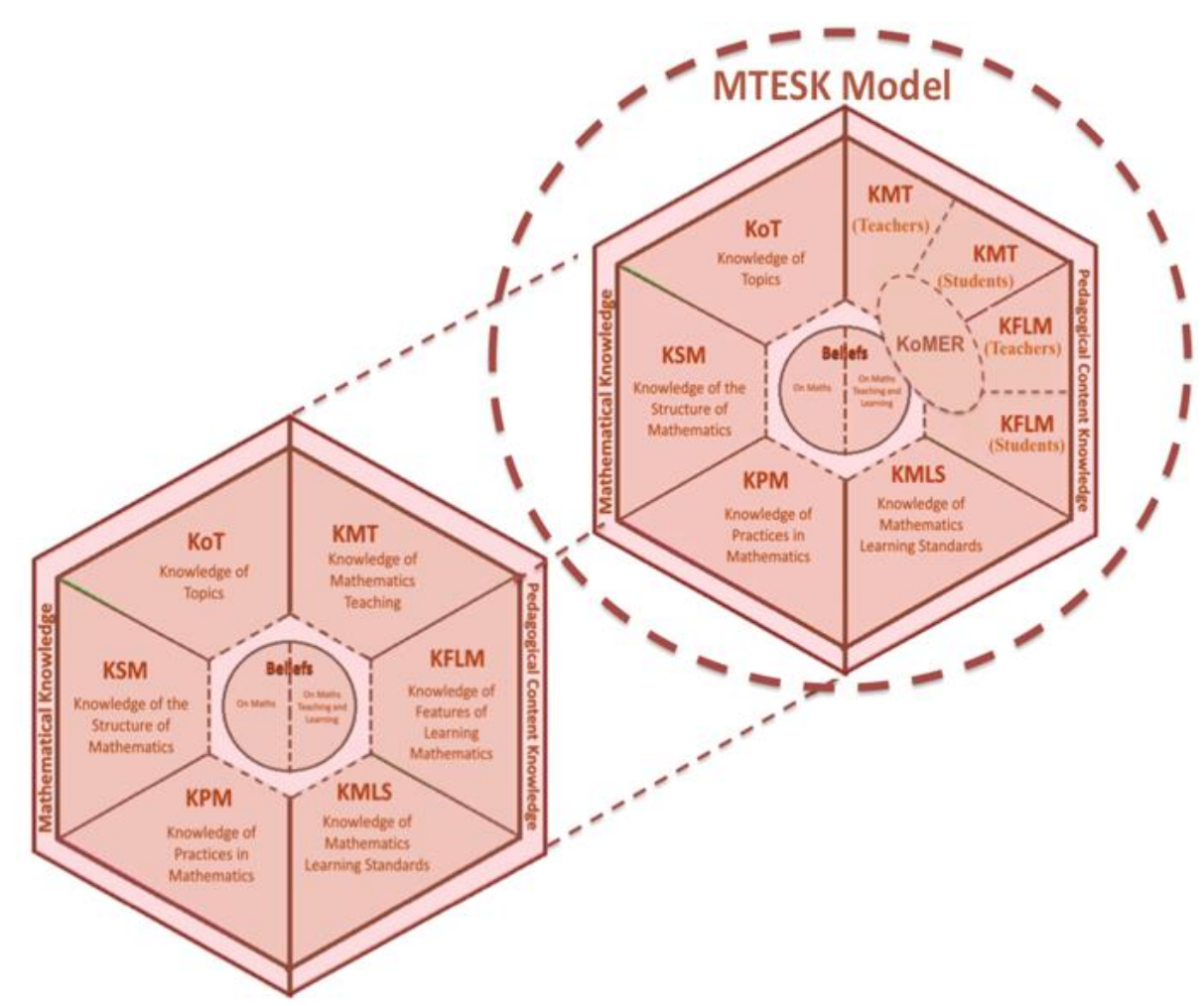

Figure 2. Frist draft of the Mathematics Teacher Educator Specialised Knowledge - MTESK model Souce: Martignone et al. (submitted)

\section{MTEs' Pedagogical Content Knowledge}

In this section we provide examples of excerpts from the MTE's interviews to illustrate some of the features that lead us to rise the hypothesis about the existence of new subdomains and subdivisions inside PCK subdomains of the MTSK. For the exploration of the subdomains we will use short extracts extrapolated from the interviews conducted with MTEs. The MTEs are in-service and/or pre-service teacher educators and they are researchers in mathematics education and teachers.

\section{KMT - teachers}

The existence of this subdivision inside the KMT responds to the need of provide a space of its own to the activity of teaching teachers, which is one of the MTE's roles. From this point of view, the original KMT that in the MTSK model concerns the features of mathematics teaching, here includes a specific area about how to teach mathematics to mathematics teachers, which are students at that moment but never abandon their facet as teachers, even during their own training (Tzur, 2001; Jaworski, 2008). Thus, considering that the description of KMT in MTSK includes different strategies allowing teacher to promote the development of mathematical abilities, in the case of KMT-teachers in MTESK this subdomain concerns strategies, or meta-strategies, allowing MTE to promote among teachers' mathematics teaching skills, to make the most of mathematics teachers abilities to 
promote mathematical thinking among their students (Aldon et al. 2013). We examine this with the following two examples.

The first one comes from a researcher in mathematics education, teaching at university level, training both pre-service and in-service mathematics teachers in different courses with few years of experience as MTE:

TI_02 [Researcher of math education/ In-service and Pre-service teachers TE]: I believe that a good teacher educator is able to balance between theory and practice. Between principles and examples. Sometimes one can adopt a top-down approach (from theory to examples), other times a bottom-up approach (from examples, provided by the teachers themselves, to theory). [...] teachers love to be listened. To feel that they are cared about. They like to discuss with their colleagues, and they like to engage in discussions with the teacher educator. So, one who provides opportunity for talking does not only allow teachers to 'feel good', but also enhances interpersonal skills, deeper understanding of the subject and a sense of connection with the class.

As we can see in this excerpt, the interviewed MTE points out the need of promoting deeper understanding by exploring and experiencing different teaching approaches (topdown, bottom-up) and also the convenience of creating a space of fluent communication and discussion.

The second example comes from a more experienced MTE, also university professor and a mathematics education researcher, training pre-service and in-service teachers:

TI_01 [Researcher of math education/ In-service and Pre-service teachers TE]: I believe that a good mathematics TE is able to translate her/his theoretical knowledge into activities, which trainee teachers live as in first person experiences, discussed and shared in the social environment of the training course.

In this second excerpt we observe another shade of a meta-didactical transposition (Aldon et al., 2013; Robutti, 2020): translating his/her knowledge (assuming based on research or experience) into activities to be discussed and shared with teachers.

\section{KMT - students}

From the interviews we observed that when MTE referred to features that could be assigned to KMT there are some differences when they consider teachers or teachers' students. The orientation of the answers was significantly different and that is why we postulate the existence of a possible division within KMT into teachers and students. In the case of KMT-students, MTEs insisted in providing mathematics teachers with tools to efficiently deal with teaching mathematics in the 21 st Century. The following excerpt comes from a Spanish TE interview.

TS_01 [Researcher of math education/ Pre-service teachers TE]: it would be good that he/she could use innovative technological resources, because nowadays different 
DOI: $10.20396 /$ zet.v29i00.8661966

instruments are developed for facing the learning with a greater efficiency, or for motivating students for making learning more efficient, or at least effective.

In this case we can see how the focus of MTE's discourse moved from teachers to students (teachers' pupils), therefore the MTE is talking about features of mathematics teaching but going beyond the teaching MTE-mathematics teacher to the space mathematics teacher-students. We think this can support the existence of the proposed duality within KMT.

\section{KFLM - teachers}

As in the case of KMT, we have observed how when MTE discussed about the features of learning mathematics, they unfold their speech into two subjects: the trained teachers and the students that will be taught by them. Thus, we also suggest dividing the KFLM into two areas, one for teachers and one for students. Let us examine the following example, coming from a MTE who is applied mathematics university professor but has been involved in in-service teacher education programs in the last years.

TS_01 [Researcher of math education/ Pre-service teachers TE]: What I think the most about it for improving my work as TE is learning to value the diversity in the class. That is, how students with notably different backgrounds and notably different mathematical knowledge could become levelled in order to teach mathematics with the required rigor.

The answer focus on how pre-service teachers having different backgrounds (mathematicians, physicists, engineers, etc.) should acquire a common core of training features qualifying them to become mathematics teachers. It is also noticeable how this MTE underlines the rigor of mathematics, which is something less present in answers coming from mathematics education researchers.

\section{KFLM students}

The other subdivision of the KFLM is centred on students features, considering teachers' pupils and not teachers themselves as students. Some MTEs made a precise distinction between learning features of the former and of the latter. We can illustrate it with the following excerpt from the interview to an Italian MTE.

TI_01 [Researcher of math education/ In-service and Pre-service teachers TE]: Mathematics teachers should take into account aspects related to the development of the pupil's personality as crucial general objectives that are related to the learning of mathematics.

In the transcript we note the mention to pupil's personal development as something that should be considered by both mathematics teachers and MTE.

\section{KoMER}

As highlighted in Zeichner (2005), the preparation of teacher educators needs to include some attention to the conceptual and empirical literature and these aspects emerge in the words of TE interviewed in our study. As we pointed out above, the existence of a 
transversal subdomain within the PCK of MTESK corresponding to the knowledge of educational research in mathematics is another hypothesis that we raise from our study. The knowledge of mathematics educational research for a mathematics teacher could be what the main trends in mathematics educational research say about the teaching and learning processes in mathematics and about students' features. But in the case of MTE, this is a much deeper knowledge, since he/she needs to be in constant updating about recent research, in order to incorporate latest developments and results into the teacher education programs, either in-service or pre-service. Moreover, MTEs may also be involved in research groups or initiatives where they can work and discuss with researchers in mathematics education. In the following, we show three MTEs' opinions about this issue.

TI_03 [Primary teachers/ In-service teachers TE]: To know the main aspects of national and international educational research in mathematics in order to make the evolutionary feature of mathematical knowledge more and more explicit.

This first excerpt makes a clear statement about the needed knowledge. In this case it could be also admitted for mathematics teachers, since it is pointing out only to the "main aspects".

TI_01 [Researcher of math education/ In-service and Pre-service teachers TE]: Mathematics education literacy is fundamental to become a TE, since it provides the tools to understand, interpret and foresee the cognitive, emotional and social behaviour of students, struggling to learn mathematics. Furthermore, mathematics education provides powerful tools to design appropriate mathematics curricula, assessment approaches and teaching methods and strategies

This second excerpt is much clearer about the distinction between mathematics teacher and MTE, since it underlines the role of mathematics educational research in the design of training programs (here "students" must be interpreted in terms of teachers being trained).

TI_04 [Secondary teachers /In-service and Pre-teachers TE]: Be aware of the didactics of the discipline and in contact with the results of mathematics educational research.

This third excerpt remarks the updating as a main characteristic of the knowledge in the case of MTE, but also the need to keep in contact with the results, which can also be viewed in terms of contact with communities of research and learning.

\section{Final remarks}

In this paper we describe the Mathematics Teacher Educator Specialized Knowledge model - MTESK model (see Figure 2): in particular, our focus is on the Pedagogical Content Knowledge of the MTESK model. The MTESK model was introduced (Martignone et al., submitted) by using the result of a qualitative analysis of MTE's answers about what knowledge they think it was important to be a "good" teacher educator, and it was based on 
MTSK model by Carrillo-Yáñez et al. (2018). In particular, our focus is on Pedagogical Content Knowledge in the MTESK model. We stress the importance of Knowledge of Research in Mathematics Education (KoMER): this subdomain is not distinct but closely connected and transversal to the subdomains KMT and KFLM. KoMER for MTES goes further than a basic knowledge: it is linked to keep updated about recent research in mathematics education and the relationship with researchers and University. Moreover, we highlight that in the MTESK model it is necessary to distinguish whether teaching and learning aspects of mathematics refer to the teaching/learning processes of students or teachers. In the previous paragraph, we show some excerpts from MTEs' interviews in order to support the specific features added in the MTESK model.

We conclude by remarking that in Figure 2 the MK domain is divided into three subdomains (KoT, KSM, and KPM) as in the MTSK Model. This does not mean that there can be no difference even in this part of the models between the specialized knowledge of teacher and teacher educator, but in our interviews, it only emerged that it should be more extensive and in-depth, but this issue has to be further investigated. In fact, this is one of the aspects we plan to investigate deeper in our future research. By now, being inspired by the MTSK model, we are naming the domain as mathematical knowledge, but it is possible that, by keeping the original Shulman's formulation, maybe it is more accurate to talk about "mathematical teacher educator knowledge" (a kind of MTE-K), by considering that the MTE's content knowledge is different (even when it could contain it) from a mathematics teacher's content knowledge, which is that was denoted by MK in the MTSK. Thus, we need further research in order to determine the domain "mathematical knowledge" in the case of the MTESK, which is something already pointed out in Escudero-Ávila, Montes, and Contreras (2021).

\section{Acknowledgments:}

Funding: Francesca Martignone is supported by Grant FAR 2017- University Funds for Research - Department of Science and Technological Innovation of the University of Eastern Piedmont. Luis J. Rodríguez-Muñiz is supported by Grant TIN2017-87600-P, Ministry of Science and Innovation of Spain.

\section{References}

Aldon, G., Arzarello, F., Cusi, A., Garuti, R., Martignone, F., Robutti, O., Sabena, C., \& Soury-Lavergne, S. (2013). The meta-didactical transposition: a model for analysing teachers education programs. In Lindmeier, A. M. \& Heinze, A. (Eds.). Proceedings of the 37th Conference of the International Group for the Psychology of Mathematics Education (Vol. 1, pp. 97-124). Kiel, Germany: PME.

Ball, D. ., Thames, M. H., \& Phelps, G. (2008). Content knowledge for teaching: What makes it special? Journal of Teacher Education, 59(5), 389-407. 
Beswick, K., \& Goos, M. (2018). Mathematics teacher educator knowledge: What do we know and where to from here? Journal of Mathematics Teacher Education, 21, 417-427.

Carrillo-Yáñez, J., Climent, N., Montes, M., Contreras, L.C., Flores-Medrano, E., EscuderoÁvila, D., ... Muñoz-Catalán, M.C. (2018). The mathematics teacher's specialised knowledge (MTSK) model. Research in Mathematics Education, 20(3), 236-253.

Escudero-Ávila, D., Montes, M., \& Contreras, L.C. (2021). What do mathematics teacher educators need to know? Reflections emerging from the content of mathematics teacher education. In M. Goos, \& K. Beswick (Eds.), The Learning and Development of Mathematics Teacher Educators, (pp. to appear). Cham, Switzerland: Springer.

Even R., Krainer K., Huang R. (2020). Education of Mathematics Teacher Educators. In: Lerman S. (eds), Encyclopedia of Mathematics Education. Springer, Cham.

Flores, E., Escudero, D. I., \& Carrillo, J. (2013). A theoretical review of specialised content Knowledge. In B. Ubuz, C. Haser \& M. A. Mariotti (Eds.), Proc. VIII Congress of the European Society for Research in Mathematics Education (CERME 8) (pp. 3055-3064). Antalya, Turkey: Middle East Technical University, Ankara.

Krainer K., Chapman O., Zaslavsky O. (2020). Mathematics Teacher Educator as Learner. In Lerman S. (eds) Encyclopedia of Mathematics Education. Springer, Cham.

Jaworski, B. (2008). Mathematics teacher educator learning and development: An introduction. In International Handbook of Mathematics Teacher Education (Vol. 4, pp. 1-13). Brill Sense.

Llinares, S., \& Krainer, K. (2006). Mathematics (student) teachers and teacher educators as learners. In A. Gutiérrez \& P. Boero (eds.), Handbook of research on the psychology of mathematics education (pp. 429-459). Brill Sense.

Loughran, J. (2014). Professionally developing as a teacher educator. Journal of teacher education, 65(4), 271-283.

Martignone, F., Ferretti, F., \& Rodríguez-Muñiz (submitted). What should be the specialised knowledge of a mathematics teacher educator?

Montes, M. A., Aguilar, A., Carrillo, J., \& Muñoz-Catalán, M. C. (2013). MTSK: from common and horizon knowledge to knowledge of topics and structures. In B. Ubuz, C. Haser \& M. A. Mariotti (Eds.), Proc. VIII Congress of the European Society for Research in Mathematics Education (CERME 8) (pp. 3185-3194). Antalya, Turkey: Middle East Technical University, Ankara.

Patton, M. (2002). Qualitative research and evaluation methods. London, UK: Sage Publications.

Prediger, S., Roesken-Winter, B., \& Leuders, T. (2019). Which research can support PD facilitators? Strategies for content-related PD research in the Three-Tetrahedron, Model. Journal of Mathematics Teacher Education, 22, 407-425.

Rasmussen, C., Zandieh, M,. \& Wawro, M. (2009). How do you know which way the arrows go? The emergence and brokering of a classroom mathematics practice. In W.M. Roth (Ed.), Mathematical representations at the interface of the body and culture (pp. 171218). Charlotte: Information Age Publishing. 
DOI: $10.20396 /$ zet.v29i00.8661966

Ribeiro, M., Martignone, F., Aslan-Tutak, F., Rø, K., \& Montes, M. (2019). Introduction to the papers of TWG20: Mathematics teacher knowledge, beliefs, and identity. In: U. T. Jankvist, M. van den Heuvel-Panhuizen, \& M. Veldhuis (Eds.), Proceedings of the Eleventh Congress of the European Society for Research in Mathematics Education, (pp. 3811-3814). Utrecht, the Netherlands: Freudenthal Group \& Freudenthal Institute, Utrecht University and ERME.

Robutti O. (2020) Meta-didactical Transposition. In: Lerman S. (eds) Encyclopedia of Mathematics Education. Springer, Cham.

Shulman, L. (2008). Content knowledge for teaching: What makes it special. Journal of Teacher Education, 59(5), 389-407.

Tzur, R. (2001). Becoming a mathematics teacher-educator: Conceptualizing the terrain through self-reflective analysis. Journal of Mathematics Teacher Education, 4(4), 259283.

Zeichner, K. (2005). Becoming a teacher educator: A personal perspective. Teaching and teacher education, 21(2), 117-124. 